\title{
EL SERVICIO PÚBLICO ESENCIAL Y DERECHO DE HUELGA EN COLOMBIA (CONVENIOS 87 Y 98 DE LA OIT)
}

\author{
Francisco Rafael Ostau de Lafont de León \\ Leidy Ángela Niño Chavarro \\ Universidad Católica de Colombia
}

\section{Resumen}

El presente artículo planteará una solución a la controversia surgida una vez aprobada la Constitución de 1991, en la cual se establecen dos normas en materia del mundo del trabajo (Derecho Laboral): el Artículo 53 que dispone: "[...] Los convenios internacionales del trabajo debidamente ratificados, hacen parte de la legislación interna [...]" y el Artículo 93 que señala: "Los tratados y convenios internacionales ratificados por el Congreso, que reconocen los derechos humanos y que prohíben su limitación en los estados de excepción, prevalecen en el orden interno [...]". Estas normas han causado que los Convenios 87 y 98 de la OIT (ratificados por Colombia mediante las Leyes 26 y 27 de 1976, respectivamente) y los comentarios de sus órganos de control (Comité de Libertad Sindical y de la comisión de expertos en aplicación de convenios y recomendaciones) sean considerados por la Corte Constitucional como convenios de derechos humanos que forman parte del bloque de constitucionalidad; esto genera una contradicción con el Código Sustantivo frente al ejercicio del derecho de huelga. Se tendrá como objeto definir el concepto de servicio público esencial y el derecho de huelga, las causales de declaratoria de ilegalidad de la suspensión o del paro colectivo de actividades y cuántos tipos de huelga hay en Colombia.

Palabras clave: huelga, Derecho Internacional, servicio público esencial, Constitución.

Los autores: Francisco Rafael Ostau de Lafont de León es filósofo, especializado en Derecho Laboral y Acción Social, doctor en Derecho y Ciencias Políticas, doctor en Derecho y doctor en Sociología Jurídica e Instituciones Políticas. Dirige la línea de investigación de Derecho Público del Grupo de investigación sociojurídico del Centro de Investigaciones de la Universidad Libre de Colombia. Dirección postal: carrera 18 No.39A-46. Correo electrónico: paco_syares@yahoo.es

Leidy Ángela Niño Chavarro es abogada, especialista en Derecho Laboral y Seguridad Social y maestranda en Derecho del Trabajo. Es docente investigadora del Centro de Investigaciones de la 
Corporación Universitaria Republicana. Dirección postal: carrera 18 No. 39A-46. Correo electrónico: angie_nomore@yahoo.es

Recibido: 11 de marzo de 2014; evaluado: 21 de abril de 2014; aceptado: 27 de mayo de 2014.

\title{
ESSENTIAL PUBLIC SERVICE AND THE RIGHT TO STRIKE IN COLOMBIA (CONVENTIONS No. 87 AND 98 OF ILO)
}

\author{
Francisco Rafael Ostau de Lafont de León \\ Leidy Ángela Niño Chavarro \\ Universidad Católica de Colombia
}

\begin{abstract}
This paper will set out a solution to the controversy that emerged after the approval of the Constitution of 1991, in which two norms in the matter of labour (Labour Law) were established: Article 53 mandates "(...) International conventions of labour duly ratified are part of the internal law. (...)"; and Article 93 states "International treaties and conventions ratified by Congress that recognize Human Rights and prohibit their limitations in state of exception, prevail in the internal order (...)". This norms have produced that the Convention No. 87 and 98 of ILO (ratified by Colombia through law 26 and 27 of 1976 respectively) and the comments of their supervisory bodies (Trade Union Freedom Comittee and the Committee of Experts on the Application of Conventions and Recommendations) be considered by the Constitutional Court as conventions of human rights that are part of the constitutionality block. This has resulted in a contradiction of the substantive code addressing the exercise of the right to strike. The purpose of this article will be to establish the concept of essential public service and the right to strike, the grounds of illegality declaration of collective halt or suspension of activities, and the different types of strike in Colombia.
\end{abstract}

Keywords: Strike, international law, essential public service, Constitution.

About the authors: Francisco Rafael Ostau de Lafont de León is Doctor in Law, with specialty in Labour Law and Social Action of the Faculty of Law; Doctor in Law; Doctor in Sociology of Law and Political Institutions. Director of the area of research in Public Law of the socio-legal research group at the Universidad Libre de Colombia. Address: Carrera 18 No.39A-46. E-mail: paco_syares@yahoo.es. 
Leidy Ángela Niño Chavarro is a laywer with specialty in Labour Law and Social Security from Universidad del Rosario and candidate to a Labour Law Masters degree. Researcher and professor at the Reseach Center of Corporación Universitaria Republicana. Address: Carrera 18 No. 39A-46.

E-mail: angie_nomore@yahoo.es

Received: March 11, 2014; reviewed: April 21, 2014; accepted: May 27, 2014. 


\section{Introducción}

Al consagrar en su artículo 93 la posibilidad de que los convenios de la Organización Internacional del Trabajo (OIT) formen parte del ordenamiento interno, la Constitución Política de 1991 instituyó que los Convenios 87 y 98 de la OIT, que versan sobre derechos humanos, prevalecen sobre el contenido del Código Sustantivo del Trabajo (CST). Aclarado lo anterior, respecto al derecho de huelga en Colombia es necesario señalar, entre otras, las siguientes contradicciones existentes en nuestra legislación laboral:

El Artículo 430 del CST preceptúa la prohibición de la huelga en los servicios públicos; el Artículo 56 de la Constitución Política de 1991 garantiza el derecho de huelga salvo en los servicios públicos esenciales, los cuales deberán ser regulados por la ley. Al no reglamentarse el concepto de servicios públicos esenciales en Colombia iqué efectos produce esta negativa frente al ejercicio del derecho de huelga, de conformidad con el Convenio 87 de la OIT?

Debido a que el Artículo 450 del CST precisa las causales de declaratoria de ilegalidad de la suspensión o del paro colectivo de actividades, se mantiene la ilegalidad de la huelga en los servicios públicos; frente a esta situación ¿cuál es la problemática que se presenta en la declaratoria de ilegalidad de la suspensión o del paro colectivo de actividades en los servicios públicos esenciales?

En su Artículo 429, el CST define la huelga y su reglamentación y se refiere a una sola clase: la huelga de pliego de peticiones. De la lectura que ha hecho el Comité de Libertad Sindical sobre los Convenios 87 y 98 de la OIT se han extraído varios tipos de huelga. Por lo contrario, en la legislación laboral colombiana se reconoce y reglamenta la huelga de pliego de peticiones y se reconoce la huelga por no pago de salarios y obligaciones laborales. Así las cosas ¿cuántas clases de huelga existen en Colombia?

\section{Problema de investigación}

El problema de investigación giró en torno a formular la solución a la contradicción existente entre el Código Sustantivo de Trabajo de 1950 y la Constitución Política de 1991 en materia del derecho de huelga, en aplicación del bloque de constitucionalidad dentro del marco de los Convenios 87 y 98 de la OIT. 


\section{Hipótesis de trabajo}

La contradicción que se plantea entre la Constitución de 1991 y el Código Sustantivo del Trabajo podría ser resuelta con la jurisprudencia de la Corte Constitucional y los criterios de interpretación de los órganos de control de la OIT sobre los Convenios 87 y 98 de la OIT, dentro del concepto y de la aplicación del bloque de constitucionalidad.

\section{Estrategia metodológica}

Se empleó el análisis del discurso normativo de la Constitución Política de 1991, de los Convenios 87 y 98 de la OIT, del Código Sustantivo del Trabajo en materia de derecho de huelga y el análisis del discurso de los organismos de control de la OIT, en el marco de la jurisprudencia de la Corte Constitucional colombiana.

\section{Resultados}

\section{El concepto de servicio público esencial y el derecho de huelga}

El Código Sustantivo de Trabajo en Colombia fue expedido en 1950 mediante los Decretos de estado de sitio $^{1} 2663$ y 3740 , adoptados como legislación permanente por la Ley 141 de 1961. Esta normativa laboral tiene como fundamento la Constitución de 1886 y, en materia del mundo del trabajo, la reforma constitucional de 1936 que en su Artículo $18^{2}$ expresó: "Se garantiza el derecho de huelga, salvo en los servicios públicos. La ley reglamentará su ejercicio". ${ }^{3}$ Al reglamentar el derecho de huelga, el Código Sustantivo del Trabajo indicó en el Artículo $429^{4}$ que la huelga "es la suspensión colectiva, temporal y pacífica del trabajo efectuada por los trabajadores de un establecimiento o empresa con fines económicos o profesionales propuesta a su patrono". Asimismo, en el Artículo 430 instaura la prohibición de la huelga en los servicios públicos y define que "son servicios públicos toda actividad

En la Constitución de 1986 se estableció como estado de sitio lo que hoy se conoce como estado de excepción.

2 Colombia, Congreso de la República, Acto legislativo 01 de 1936, "Reformatorio de la Constitución" (Bogotá: Diario Oficial No. 23.263, 22 de agosto de 1936).

3 "Es permitido formar compañías, asociaciones y fundaciones que no sean contrarias a la moral o al orden legal. Las asociaciones y fundaciones pueden obtener su reconocimiento como personas jurídicas. Se garantiza el derecho de huelga, salvo en los servicios públicos. La ley reglamentará su ejercicio". Colombia, Congreso de la República, Acto legislativo 01 de 1936, art. 20.

4 Colombia, Congreso de la República, Código Sustantivo del Trabajo (Bogotá: Leyer, 2012). 
organizada que tienda a satisfacer necesidades de interés general en forma regular y continua". Acto seguido, enuncia las actividades que son consideradas servicio público: aquel que preste cualquiera de las ramas del poder público, las empresas de transporte por tierra, agua y aire, acueducto, energía eléctrica y telecomunicaciones, las de establecimientos sanitarios de toda clase, hospitales, clínicas, las de establecimientos de asistencia social y beneficencia, entre otras. ${ }^{5}$

Más adelante, la Constitución de 1991 indicó en su Artículo $56^{6}$ que "se garantiza el derecho de huelga, salvo en los servicios públicos esenciales definidos por el legislador", lo que produjo una contradicción frente al ejercicio del derecho de huelga tal y como se establece en el Código Sustantivo (servicio público) o conforme a los preceptos constitucionales de la Carta de 1991 (servicio público esencial).

Al respecto, la Corte Constitucional ha reiterado que el derecho de huelga, incluido el Artículo 450 del CST, debe partir de la lectura de los servicios públicos esenciales. ${ }^{7}$ En efecto, respecto al servicio público esencial, ${ }^{8}$ esta Corporación ha señalado que:

[...] corresponde al Congreso de la República definir los servicios públicos esenciales, sin perjuicio de que la Corte Constitucional, posteriormente, pueda hacer uso de la potestad de ejercer el control de constitucionalidad en relación con las disposiciones legales que para el efecto se dicten. Estima la Corte que es primordial y urgente que el Legislador proceda a desarrollar el precepto constitucional, a fin de precisar las actividades constitutivas del servicio público esencial, y con el objeto de garantizar en plenitud el ejercicio del derecho de huelga en aquellas labores que no tienen esa característica. ${ }^{9}$

En sentencia,${ }^{10}$ la Corte determinó que el carácter esencial de un servicio público se establece cuando este contribuye de manera directa a la protección de bienes, a la

5 Algunas de las actividades señaladas han sido reglamentadas mediante leyes que las catalogan como servicios públicos esenciales.

6 En sentencia se declaró exequible el inciso 1 del Artículo 430 del Código Sustantivo del Trabajo, "siempre que se trate, conforme al artículo 56 de la Constitución Política, de servicios públicos esenciales definidos por el Legislador". Colombia, Corte Constitucional, Sentencia C-473 de 27 de octubre de 1994, M. P. Alejandro Martínez Caballero. Lo anterior fue reiterado en Colombia, Corte Constitucional, Sentencia C-075 de 20 de febrero de 1997, M. P. Hernando Herrera Vergara y en Colombia, Corte Constitucional, Sentencia C-542 de 23 de octubre de 1997, M. P. Hernando Herrera.

7 Colombia, Corte Constitucional, Sentencia C-473 de 27 de octubre de 1994.

8 Colombia, Corte Constitucional, Sentencia C-450 de 4 de octubre de 1995, M. P. Antonio Barrera Carbonell; Colombia, Corte Constitucional, Sentencia C-075 de 20 de febrero de 1997.

9 Colombia, Corte Constitucional, Sentencia C-075 de 20 de febrero de 1997.

10 Colombia, Corte Constitucional, Sentencia C-450 de 4 de octubre de 1995. 
satisfacción de intereses o a la realización de valores, en conjunto con el respeto, la vigencia, el ejercicio y la efectividad de los derechos y las libertades fundamentales. En este caso, el derecho de huelga debe ceder frente a los derechos fundamentales y es este el fundamento de la Corte para declarar exequibles los literales b) y h) del Artículo 430 del CST, que señalan:

b) las empresas de transporte por tierra, agua y aire; y de acueducto, energía eléctrica y telecomunicaciones; [...] h) Las de explotación, refinación, transporte y distribución de petróleos y sus derivados, cuando estén destinadas al abastecimiento normal de combustibles del país, a juicio del gobierno.

A pesar del reiterado requerimiento de la Corte Constitucional al legislador sobre la necesidad de definir y reglamentar las actividades consideradas como servicio público esencial con fundamento en el Artículo $56 \mathrm{CP}$, esto no se ha llevado a cabo. Solo en la medida en que se han producido normas alrededor de alguna actividad se ha ido introduciendo la expresión "servicio público esencial" en el campo del Derecho Laboral colectivo para señalar su prohibición en dicha actividad, como sucede en el caso de servicios públicos domiciliarios (Ley 142 de 1994), administración de justicia (Ley 270 de 1996), seguridad social en salud y pago de pensiones (Ley 100 de 1993), banca central (Ley 31 de 1992), el servicio que presta el Instituto Nacional Penitenciario (Inpec) (Decreto 407 de 1994), Transporte (Ley 336 de 1996), Bomberos (Ley 322 de 1996), las actividades de la Dirección de Aduanas e Impuestos Nacionales (DIAN) (Ley 633 de 2000), explotación del petróleo (Corte Constitucional, Sentencia C-450 de 1995), la educación (Sentencia C-423 de 1996).

Varias de estas actividades coinciden con la definición de servicio público esencial que ha establecido con claridad el Comité de Libertad Sindical y la Comisión de expertos en aplicación de convenios y recomendaciones; sin embargo, existen otras actividades que no son consideradas como servicios esenciales por parte de los órganos de control de la OIT, sino como servicios públicos con la obligación de prestar un servicio mínimo.

De conformidad con la jurisprudencia de la Corte Constitucional, ${ }^{11}$ tanto los Convenios 87 y 98 como la Recomendación 92 de la Organización Internacional del Trabajo (OIT) han sido considerados referentes a derechos humanos y, por lo tanto,

11 Colombia, Corte Constitucional, Sentencia T-568 de 10 de agosto de 1999, M. P. Carlos Gaviria Díaz; Colombia, Corte Constitucional, Sentencia C-567 de 17 de mayo de 2000, M. P. Alfredo Beltrán Sierra; Colombia, Corte Constitucional, Sentencia T-285 de 5 de abril de 2006, M. P. Álvaro Tafur Galvis. 
prevalecen en el orden interno. Estos Convenios tienen control internacional por parte de la Organización Internacional del Trabajo desde dos organismos internos: el Comité de Libertad Sindical (CLS) y la Comisión de expertos en aplicación de convenios y recomendaciones (CEACR). Estos órganos han señalado diversos criterios sobre la aplicación de los mencionados Convenios y se consideran guías de aplicación e interpretación. ${ }^{12}$

Es importante que los operadores judiciales colombianos en materia de Derecho Laboral tengan presentes las implicaciones del bloque de constitucionalidad, ${ }^{13}$ ya que permite la efectividad plena de los derechos constitucionales en el mundo del trabajo. Sobre el bloque de constitucionalidad, ${ }^{14}$ la Corte Constitucional señala el carácter normativo y obligatorio de los Convenios de la OIT ratificados por Colombia y en especial los Convenios 87 y 98 que forman parte del mismo en sentido estricto. ${ }^{15}$

12 Xavier Beaudonnet, ed. International Labour Law and Domestic Law Subtitle: Training Manual for Judges, Lawyers and Legal Educators (Turín: OIT, 2009), 92.

13 Francisco Rafael Ostau de Lafont y Leidy Ángela Niño Chavarro, "Aplicación de los Convenios de la OIT en materia de derecho de asociación sindical y negociación colectiva en las decisiones de los jueces laborales en Colombia. Prolegómenos". Derechos y Valores, núm. XIII (julio-diciembre, 2010), 45.

14 "[...] el bloque de constitucionalidad está compuesto por aquellas normas y principios que, sin aparecer formalmente en el articulado del texto constitucional, son utilizados como parámetros del control de constitucionalidad de las leyes, por cuanto han sido normativamente integrados a la Constitución, por diversas vías y por mandato de la propia Constitución. Son pues verdaderos principios y reglas de valor constitucional, esto es, son normas situadas en el nivel constitucional, a pesar de que puedan a veces contener mecanismos de reforma diversos al de las normas del articulado constitucional stricto sensu. En tales circunstancias, la Corte Constitucional coincide con la Vista Fiscal en que el único sentido razonable que se puede conferir a la noción de prevalencia de los tratados de derechos humanos y de derecho internacional humanitario (CP arts. 93 y 214 numeral $2^{\circ}$ ) es que éstos forman con el resto del texto constitucional un bloque de constitucionalidad', cuyo respeto se impone a la ley. En efecto, de esa manera se armoniza plenamente el principio de supremacía de la Constitución, como norma de normas ( $\mathrm{CP}$ art. $4^{\circ}$ ), con la prevalencia de los tratados ratificados por Colombia, que reconocen los derechos humanos y prohíben su limitación en los estados de excepción (CP art. 93). Como es obvio, la imperatividad de las normas humanitarias y su integración en el bloque de constitucionalidad implica que el Estado colombiano debe adaptar las normas de inferior jerarquía del orden jurídico interno a los contenidos del derecho internacional humanitario, con el fin de potenciar la realización material de tales valores". Colombia, Corte Constitucional, Sentencia T-568 de 10 de agosto de 1999. Expediente 206.360, M. P. Carlos Gaviria Díaz.

15 "La jurisprudencia de esta Corporación ha establecido (i) en primer lugar, que los convenios de la OIT hacen parte de la legislación interna, de conformidad con el inciso 4 del artículo 53 de la $\mathrm{CN}$; (ii) en segundo lugar, que varios convenios de la OIT hacen parte del bloque de constitucionalidad; (iii) en tercer lugar, ha realizado una distinción entre los convenios de la OIT para señalar que alguno de ellos pertenecen al bloque de constitucionalidad en sentido estricto (inciso 1 art. $93 \mathrm{CN}$ ) y en sentido lato (inciso $2^{\circ} \mathrm{CN}$ ). Los convenios que hacen parte del bloque de constitucionalidad en sentido estricto prevalecen en el orden interno, en cuanto prohíben la limitación de un derecho humano bajo los estados de excepción y en consecuencia hacen parte del parámetro de control constitucional de las normas legales que regulan la materia. Los convenios que forman parte del bloque de constitucionalidad en sentido lato sirven como referente para interpretar los derechos de los trabajadores y darle plena efectividad al principio fundamental de la 
En consecuencia, los Convenios 87 y 98 de la OIT, ratificados por Colombia mediante las Leyes 26 y 27 de 1997, son de derechos humanos y, por ende, parte del bloque de constitucionalidad; estos, con sus elementos interpretativos del Comité de Libertad Sindical y la Comisión de expertos en aplicación de convenios y recomendaciones, prevalecen sobre el Código Sustantivo del Trabajo y las normas que han considerado estas actividades como servicio público esencial. Los criterios del Comité de Libertad Sindical han establecido que:

[...] el derecho de huelga puede limitarse o prohibirse: 1) en la función pública sólo en el caso de funcionarios que ejercen funciones de autoridad en nombre del Estado, o 2) en los servicios esenciales en el sentido estricto del término (es decir, aquellos servicios cuya interrupción podría poner en peligro la vida, la seguridad o la salud de la persona en toda o parte de la población). ${ }^{16}$

Al respecto, ha señalado:

Lo que se entiende por servicios esenciales en el sentido estricto de la palabra depende en gran medida de las condiciones propias de cada país. Por otra parte, este concepto no es absoluto puesto que un servicio no esencial puede convertirse en servicio esencial cuando la duración de una huelga rebasa cierto período o cierto alcance y pone así en peligro la vida, la seguridad de la persona o la salud de toda o parte de la población. ${ }^{17}$

Así, el Comité de Libertad Sindical ha insistido en que pueden ser considerados como servicios esenciales:

El sector hospitalario, los servicios de electricidad, los servicios de abastecimiento de agua, los servicios telefónicos, la policía y las fuerzas armadas,

protección del trabajador y al derecho al trabajo; (iv) en cuarto lugar, ha establecido la Corte que hacen parte del bloque de constitucionalidad aquellos convenios que la Corte misma determine que pertenecen al mismo, de conformidad con las materias de que traten. (v) Finalmente, ha establecido la Corte que el carácter normativo obligatorio de los convenios de la OIT ratificados por Colombia impide que sean considerados como parámetros supletorios ante vacíos en las leyes, y que deben ser aplicados por todas las autoridades y los particulares. Así las cosas, esta Corporación ha establecido expresamente que los convenios 87 y 98 de la OIT, hacen parte del bloque de constitucionalidad en sentido estricto. En relación con el convenio 154 de la OIT esta misma Corporación ha establecido su pertenencia al bloque de constitucionalidad". Colombia, Corte Constitucional, Sentencia C-466 de 14 de mayo de 2008, M. P. Jaime Araujo Rentería.

16 Organización Internacional del Trabajo, Libertad sindical: recopilación de decisiones y principios del Comité de Libertad Sindical del Consejo de Administración de la OIT. 5a ed. (Ginebra: Oficina Internacional del Trabajo, 2006), párr. 541.

17 Organización Internacional del Trabajo, Libertad sindical, párr. 582. 
los servicios de bomberos, los servicios penitenciarios públicos o privados, el suministro de alimentos a los alumnos en edad escolar y la limpieza de los establecimientos escolares, el control del tráfico aéreo. ${ }^{18}$

Cabe aclarar que estos criterios no pueden ser considerados como taxativos, sino elementos de carácter enunciativo.

A contrario sensu, para el mismo Comité de Libertad sindical no constituye servicios esenciales en sentido estricto:

[...] la radio-televisión, los sectores del petróleo, los puertos (carga y descarga), los bancos, los servicios de informática para la recaudación de aranceles e impuestos, los grandes almacenes y los parques de atracciones, la metalurgia y el conjunto del sector minero, los transportes en general, los pilotos de líneas aéreas, la generación, transporte y distribución de combustibles, los servicios ferroviarios, los transportes metropolitanos, los servicios de correos, el servicio de recolección de basuras, las empresas frigoríficas, los servicios de hotelería, la construcción, la fabricación de automóviles, las actividades agrícolas, el abastecimiento y la distribución de productos alimentarios, la Casa de la Moneda, la Agencia Gráfica del Estado y los monopolios estatales del alcohol, de la sal y del tabaco, empresas de embotellamiento de agua mineral. ${ }^{19}$

En casos concretos, los órganos de control de la OIT han considerado que:

[...] los trabajadores deberían poder realizar huelgas en un gran número de servicios, incluidos los siguientes: el sector bancario; los ferrocarriles; los servicios de transporte y el transporte público; los servicios de transporte aéreo y de aviación civil; los maestros y el servicio de enseñanza pública; el sector agrícola; los servicios de distribución de combustible; el sector de los hidrocarburos, el sector del gas natural y el sector petroquímico; la producción de carbón; el mantenimiento de puertos y aeropuertos, los servicios portuarios y las autoridades portuarias; la carga y descarga en muelles y atracaderos; los servicios de correo; los servicios municipales; los servicios de carga y descarga de animales y productos alimenticios perecederos; las zonas francas industriales;

18 Organización Internacional del Trabajo, Libertad sindical, párr. 585.

19 Organización Internacional del Trabajo, Libertad sindical, párr. 587. 
la imprenta oficial, y los servicios de limpieza de carreteras y recolección de basura; la radio-televisión; los servicios de hotelería; y la construcción. ${ }^{20}$

De igual manera, considera que:

[...] entre los servicios esenciales propiamente dichos pueden incluirse los servicios de control del tráfico aéreo, los servicios telefónicos y los servicios encargados de hacer frente a las consecuencias de los desastres naturales, así como los servicios de bomberos, los servicios de salud y de ambulancias, los servicios penitenciarios, las fuerzas de seguridad, y los servicios de agua y de electricidad. La Comisión estima que otros servicios (por ejemplo los servicios meteorológicos y los servicios de seguridad social) incluyen algunos elementos que pueden considerarse esenciales y otros no. ${ }^{21}$

Por lo anterior, puede concluirse que, para determinar la definición de la esencialidad o no de un servicio público, se debe convenir si su interrupción puede poner en peligro la vida, la seguridad o la salud de toda o parte de la población, a lo cual se agrega una serie de criterios auxiliares que determinan las actividades que pueden ser o no consideradas de servicios públicos esenciales.

La Organización Internacional del Trabajo ha estimado que existen servicios públicos que podrían impactar en la comunidad, pero no en su esencialidad. En este caso, su impacto negativo debe ser aminorado con la prestación de los servicios públicos mínimos, es decir, que las partes en conflicto lleguen a un acuerdo que garantice la prestación mínima de ese servicio para la comunidad, con el fin de disminuir su impacto negativo, como lo sería, por ejemplo, el transporte. Si las partes no logran un compromiso, ese servicio mínimo deberá ser establecido por la ley.

La Corte Constitucional instituyó los criterios para determinar la definición de servicio público en Colombia y preceptúo cuatro criterios que acogen los razonamientos de la OIT: primero, el carácter esencial cuando las actividades contribuyen de modo directo y concreto a la protección de bienes, a la satisfacción de intereses o a la realización de valores ligados con el respeto, la vigencia, el ejercicio y la efectividad de los derechos y las libertades fundamentales; segundo, la esencialidad del servicio está vinculada a la magnitud del mismo; tercero, el concepto de servicio público esencial que conlleva una ponderación de valores e intereses y,

Organización Internacional del Trabajo, Libertad sindical, párr. 134.

Organización Internacional del Trabajo, Libertad sindical, párr. 135. 
cuarto, el concepto de servicio público que implica una constante evolución de la situación política, económica y social. ${ }^{22}$ Con estos criterios, la Corte Constitucional ha producido elementos de juicio en el caso de decisiones de tutela, para establecer la forma como debe ser considerado un servicio público esencial. ${ }^{23}$ Además, ha declarado exequibles o inexequibles algunos apartes del Artículo 430 del CST, como es el caso de los literales b) y h); es constitucional en relación con las empresas de transporte, telecomunicaciones, explotación, refinación transporte de petróleo y sus derivados. ${ }^{24}$ En otras decisiones ha declarado inconstitucional los literales e) y g), referentes a las plantas de leche, plazas de mercado y explotaciones de sal.

Como lo señaló la Corte Constitucional en Sentencia C-858 de 2008, de conformidad con la Constitución Política de Colombia y el Convenio 87 de la OIT son servicios públicos esenciales: los servicios públicos domiciliarios, la administración de justicia, la seguridad social en salud y el pago de pensiones, no así el recaudo de las cotizaciones, la banca central, el servicio que presta el Instituto Nacional Penitenciario (Inpec), las actividades de los bomberos, las actividades de la Dirección de Aduanas e impuestos Nacionales (DIAN), los transportes aéreo, marítimo, fluvial, férreo, masivo y terrestre y su operación en el territorio nacional.

En cuanto al transporte (Ley 336 de 1996), a la explotación del petróleo (Corte Constitucional, Sentencia C-450 de 1995), a la educación (Sentencia C-423 de 1996) y a los funcionarios judiciales de los despachos, diferentes a jueces, fiscales y magistrados, que en la legislación interna han sido considerados dentro de los servicios públicos esenciales, el Comité ha expresado que podrían ser servicios públicos no esenciales, por lo que tienen la obligación de prestar un servicio mínimo. Debido a que esta situación no está reglamentada, los operadores judiciales no podrían considerar estas actividades como servicio público esencial.

De este modo, el mencionado CLS ha manifestado:

[...] que los trabajadores deberían poder realizar huelgas en un gran número de servicios, incluidos los siguientes: el sector bancario; los ferrocarriles; los servicios de transporte y el transporte público; los servicios de transporte aéreo y de aviación civil; los maestros y el servicio de enseñanza pública; el sector agrícola; los servicios de distribución de combustible; el sector de los hidro-

22 Colombia, Corte Constitucional, Sentencia C-122 de 22 de febrero de 2012, M. P. José Ignacio Pretelt.

23 Sobre los servicios de educación, salud, saneamiento ambiental y suministro de agua potable, véase Colombia, Corte Constitucional, Sentencia T-423 de 11 de septiembre de 1996, M. P. Hernando Herrera Vergara.

24 Colombia, Corte Constitucional, Sentencia C-450 de 4 de octubre de 1995. 
carburos, el sector del gas natural y el sector petroquímico; la producción de carbón; el mantenimiento de puertos y aeropuertos, los servicios portuarios y las autoridades portuarias; la carga y descarga en muelles y atracaderos; los servicios de correo; los servicios municipales; los servicios de carga y descarga de animales y productos alimenticios perecederos; las zonas francas industriales; la imprenta oficial, y los servicios de limpieza de carreteras y recolección de basura; la radio-televisión; los servicios de hotelería; y la construcción. ${ }^{25}$

En definitiva, se puede señalar que el Comité de Libertad Sindical no ha hecho una reseña absoluta de los servicios que son o no esenciales, sino que ha hecho una enumeración surgida de los casos puestos a su consideración. Respecto a las actividades no asumidas como servicios públicos esenciales, es necesario mencionar que cuando el servicio tiene un impacto en la comunidad, para la OIT puede tomarse como un servicio público que requiere una prestación mínima a la comunidad y establece los criterios sobre los servicios mínimos; ${ }^{26}$ son, entonces, las partes en conflicto quienes deben indicar la prestación del servicio mínimo y, en caso de desacuerdo, la ley estipularía la prestación mínima de los servicios a la comunidad.

\section{Causales de declaratoria de ilegalidad de la suspensión o del paro colectivo de actividades}

El Artículo 430 del CST, modificado por el Artículo 1 del Decreto extraordinario 753 de 1956, ha instaurado la prohibición de huelga en los servicios públicos, una norma que, a partir de la decisión de la Corte Constitucional, ${ }^{27}$ debe analizarse desde el concepto de servicio público esencial. Cuando el legislador elaboró la Ley 1210 de 2008, ${ }^{28}$ que trasladó la competencia de la declaratoria de ilegalidad

5 Organización Internacional del Trabajo, Libertad sindical, párr. 134.

26 Organización Internacional del Trabajo, Libertad sindical, párr. 136-138.

27 "El Constituyente estableció la noción de servicio público esencial como un límite material a la capacidad de limitación del Legislador del derecho de huelga. Es entonces ilógico suponer que el Congreso pueda redefinir, de manera discrecional, estos límites establecidos por la Constitución, lo cual sucede si el Congreso puede calificar cualquier actividad de servicio público esencial y la Corte no ejerce un control material sobre esas definiciones legales. En efecto, si el Congreso puede redefinir los límites constitucionales de un derecho fundamental, entonces el Legislador, en sentido estricto, deja de estar sujeto a la Constitución y el derecho deja de estar garantizado por la Carta. Ya con anterioridad, esta Corporación había establecido que el Legislador no puede reclamar el monopolio de la interpretación y definición de los conceptos constitucionales. Si una determinada actividad no es materialmente un servicio público esencial, no podrá el Legislador prohibir o restringir la huelga porque estaría violando el artículo 56 de la Carta". Colombia, Corte Constitucional, Sentencia C-473 de 27 de octubre de 1994.

28 Por la cual se modifican parcialmente los Artículos 448 numeral 4 y 451 del Código Sustantivo del Trabajo y 2 del Código Procesal del Trabajo y de la Seguridad Social y se crea el Artículo 129A del Código Procesal del Trabajo y de la Seguridad Social y se dictan otras disposiciones. 
de una suspensión o de un paro colectivo del trabajo del Ministerio de Trabajo a la Sala Laboral del Tribunal Superior competente en primera instancia y a la Sala Laboral de la Corte Suprema de Justicia en segunda instancia, indicó que estas deben tomar la decisión con fundamento en lo preceptuado en el Artículo 430 para la declaratoria de ilegalidad de la suspensión de actividades en los servicios públicos esenciales y de lo expresado en el Artículo 450 del CST, que reglamenta los casos de suspensión colectiva de trabajo ilegal y se circunscribe únicamente a la huelga pliego de peticiones, es decir, a la que se presenta en el marco de la negociación colectiva, según los Artículos 429 y 432 del CST.

Nuestros operadores judiciales tienen una dificultad en la aplicación de estas normas, toda vez que corresponden al Código Sustantivo del Trabajo y fueron expedidas cuando la competencia de la legalidad o ilegalidad del cese de actividades estaba en cabeza del Ministerio de Trabajo, en vigencia de la Constitución de 1986 y de la reforma de 1936, que garantizaba el derecho de huelga salvo en los servicios públicos. De aquí que deberán actuar en lo relacionado con la prohibición de la huelga en los servicios públicos, de conformidad con la Constitución de 1991, los criterios jurisprudenciales de la Corte Constitucional, los Convenios 87 y 98 de la OIT como parte del bloque de constitucionalidad y los comentarios de la Comisión de expertos en aplicación de normas y recomendaciones y del Comité de Libertad Sindical.

Se remarca esta situación por cuanto la Corte Suprema de Justicia señaló:

En suma, acorde con la aludida jurisprudencia, el derecho a la huelga ha quedado restringido de dos maneras:

a. Está prohibido su ejercicio en los servicios públicos esenciales que determine el legislador y, obviamente en los señalados como tales por el Constituyente, de acuerdo con la interpretación realizada acerca del contenido de las normas constitucionales vigentes.

b. En los demás casos, su ejercicio debe ceñirse a la reglamentación que de él haga el legislador.

Con base en las anteriores premisas, la Sala hace énfasis en lo siguiente: El literal e) del artículo 379 del Código Sustantivo del Trabajo, establece como una de las prohibiciones para los sindicatos la de "Promover cualesquiera cesaciones o paros en el trabajo, excepto en los casos de huelga 
declarada de conformidad con la ley y de huelga imputable al empleador por incumplimiento de las obligaciones con sus trabajadores.

Por tanto, dos (2) son las situaciones que posibilitan el ejercicio de la huelga por parte de los trabajadores a saber:

1.- La huelga declarada con arreglo a la ley y,

2.- La huelga imputable al empleador por incumplimiento de las obligaciones que tiene con sus trabajadores.

En cuanto a la primera, no hay duda que se refiere a la huelga que surge del conflicto colectivo de trabajo, cuando los trabajadores, al finalizar la etapa de arreglo directo, optan por esa excepcional medida de cesación de las labores de la empresa. En esta hipótesis, es incuestionable que para su declaración, inicio y desarrollo, los trabajadores interesados deben someterse a los requisitos exigidos por los artículos 444 y 445 del estatuto laboral sustantivo, en cuanto tales disposiciones forman parte del Título II del Libro Segundo del mencionado instituto que se titula como "CONFLICTOS COLECTIVOS DE TRABAJO". ${ }^{29}$

De conformidad con este pronunciamiento, la huelga que se produce por culpa del empleador, establecida en el Artículo 379 en su literal e) modificado por la Ley 584 de 2000, debe cumplir con los trámites de decisión y tiempo de la reglamentación que señala el mismo estatuto procesal para la huelga de pliego de peticiones (Artículos 444 y 445), so pretexto de que:

[...] en un Estado Social y Democrático de Derecho que garantiza el derecho de huelga pero bajo parámetros legales (artículo 56 C.P. inciso segundo), es absolutamente entendible que principios como los de oportunidad, proporcionalidad, razonabilidad y temporalidad se conjuguen con los de autonomía y libertad sindical, representación democrática laboral y defensa, de manera tal que, de consiguiente, por parte del colectivo laboral, formalmente visto o

29 Colombia, Corte Suprema de Justicia, "Sentencia del 12 de diciembre de 2012, referencia No. 58.697", http:// webcache.googleusercontent.com/search?q=cache:apvZPNaEhV8J:190.24.134.69/sentencias/Tutelas/2013/Penal/Dr.Gustavo\%2520Enrique\%2520Malo\%2520Fern\%25C3\%25Alndez/Agosto/T-68350\%2801-08-13\%29. $\mathrm{doc}+\& \mathrm{~cd}=2 \& \mathrm{hl}=\mathrm{es} \& \mathrm{ct}=\mathrm{clnk} \& \mathrm{gl}=\mathrm{co}($ acceso noviembre 20, 2013). 
informalmente organizado, deba agotarse un mínimo procedimiento para el cabal ejercicio de su derecho. ${ }^{30}$

Ante lo anterior, se encuentra que la Corte se está abrogando la facultad de legislar, al declarar la ilegalidad del cese de actividades producto de una huelga por no pago de salario y le aplica las normas para decidir la huelga que no son para este tipo de actividades, sino para la del pliego de peticiones. A la Sala Laboral de la Corte hay que recordarle su función, la cual no es legislar; por ello, debe regirse de conformidad con el Artículo 230 de la CN (imperio de la ley), toda vez que sus decisiones causan daños y conflictos sociales al aplicar el estatuto laboral según los intereses de los sujetos en conflicto. La huelga que regula el CST, definida con claridad en el Artículo 429, es aquella que se produce como consecuencia de la presentación en un pliego de peticiones y la misma normativa instaura los trámites a seguir para tal efecto. En ninguna otra norma se ha mostrado el procedimiento en caso de presentarse la huelga por no pago de obligaciones salariales, por lo que es a la propia organización sindical, dentro de su autonomía, a la que le corresponde implantar procedimientos, tiempos y formas de ejercer este tipo de huelga y no a la Corte Suprema de Justicia.

\section{3. ¿Cuántos tipos de huelga hay en Colombia?}

La huelga definida en el Código Sustantivo del Trabajo, reglamentario del Artículo 20 del Acto Legislativo de 1936 que reformó la Constitución de 1886, es la denominada huelga de negociación colectiva o huelga de pliego de peticiones, la cual se presenta por decisión de los trabajadores que han presentado tal documento y han agotado la etapa de arreglo directo. No obstante, el CLS ha señalado que la huelga es un derecho legítimo que tienen los trabajadores y sus organizaciones para la defensa de sus intereses económicos y sociales. ${ }^{31}$

El Comité ha diferenciado la huelga como un hecho sociológico de las luchas sociales y lo contempla como un derecho objetivo que tienen los trabajadores y sus organizaciones sindicales en defensa de sus intereses económicos y sociales. Al respecto señala: "520. El Comité ha estimado siempre que el derecho de huelga es uno de los derechos fundamentales de los trabajadores y de sus organizaciones

30 Colombia, Corte Suprema de Justicia, "Sentencia del 12 de diciembre de 2012, referencia No. 58.697".

31 Oficina Internacional del Trabajo, Conferencia Internacional del Trabajo. 81a reunión 1994. Informe de la Comisión de expertos en Aplicación de Convenios y Recomendaciones (Ginebra: Oficina Internacional de Trabajo, 1994), 8. 
únicamente en la medida en que constituya un medio de defensa de sus intereses económicos". 32

El CLS ha establecido que existen cuatro tipos de huelga: de pliego de peticiones o negociación colectiva, por culpa del empleador, de solidaridad y política. ${ }^{33}$ Considera que, en relación con un servicio público esencial, la huelga podría ser prohibida. ${ }^{34}$ Así, en concordancia con los criterios de la CEACR, ha reiterado en el último estudio (desarrollado en 2012) sobre los Convenios 87 y 98 para la $101 \mathrm{a}$ Conferencia Internacional del Trabajo que:

[...] son lícitas las huelgas motivadas por las políticas económicas y sociales de los gobiernos, incluidas las huelgas generales, y por lo tanto no deberían ser consideradas como huelgas puramente políticas, que no están cubiertas por los principios del Convenio. En su opinión, las organizaciones de trabajadores y de empleadores encargadas de defender los intereses socioeconómicos y profesionales deben respectivamente, poder recurrir a la huelga o a acciones de protesta para apoyar sus posiciones en la búsqueda de soluciones a los

22 Oficina Internacional del Trabajo, Conferencia Internacional del Trabajo, 126.

33 526. Los intereses profesionales y económicos que los trabajadores defienden mediante el derecho de huelga abarcan no sólo la obtención de mejores condiciones de trabajo o las reivindicaciones colectivas de orden profesional, sino que engloban también la búsqueda de soluciones a las cuestiones de política económica y social y a los problemas que se plantean en la empresa y que interesan directamente a los trabajadores.

527. Las organizaciones encargadas de defender los intereses socioeconómicos y profesionales de los trabajadores deberían en principio poder recurrir a la huelga para apoyar sus posiciones en la búsqueda de soluciones a los problemas derivados de las grandes cuestiones de política, económica y social que tienen consecuencias inmediatas para sus miembros y para los trabajadores en general, especialmente en materia de empleo, de protección social y de nivel de vida.

528. Las huelgas de carácter puramente político y las huelgas decididas sistemáticamente mucho tiempo antes de que las negociaciones se lleven a cabo no caen dentro del ámbito de los principios de libertad sindical.

529. Si bien las huelgas de naturaleza puramente política no están cubiertas por los principios de la libertad sindical, los sindicatos deberían poder organizar huelgas de protesta, en particular para ejercer una crítica contra la política económica y social del gobierno. Las organizaciones sindicales deberían tener la posibilidad de recurrir a huelgas de protesta, en particular con miras a ejercer una crítica con respecto a la política económica y social de los gobiernos.

530. En un caso en que la huelga general fue declarada como protesta contra una ordenanza sobre conciliación y arbitraje y que estaba dirigida sin duda alguna contra la política del gobierno, el Comité consideró que sería dudoso que las quejas pudieran desestimarse basándose en que la huelga no era resultado de un conflicto laboral, ya que los sindicatos estaban en conflicto con el gobierno en su calidad de empleador e importancia, como consecuencia de una medida tomada por el mismo en materia de relaciones de trabajo y que en opinión de los sindicatos limitaba el ejercicio de los derechos sindicales.

34 Oficina Internacional del Trabajo, Conferencia Internacional del Trabajo, 126. 
problemas derivados de las grandes cuestiones de política económica y social que tienen consecuencias inmediatas para sus miembros. ${ }^{35}$

En cuanto a las denominadas "huelgas de solidaridad", la Comisión estima que una prohibición general de este tipo de huelgas podría desembocar en abusos, especialmente en el contexto de la globalización (que se caracteriza por una creciente interdependencia y la internacionalización de la producción), y que los trabajadores deberían poder emprender este tipo de acciones, siempre que por su parte la huelga inicial con la que se solidarizan sea legal. Tomó nota en particular del reconocimiento en la legislación de Croacia del derecho a convocar huelgas de solidaridad, así como del hecho de que el convenio colectivo en vigor reconociera este derecho a los funcionarios públicos. ${ }^{36}$

De conformidad con lo expuesto, en virtud del bloque de constitucionalidad construido por la Corte Constitucional y de los criterios de los órganos de control de la OIT acerca de los tipos de huelga a la que tienen derecho los trabajadores que forman parte de nuestro ordenamiento interno por ser criterios de interpretación de los Convenios número 87 y 98, además de la huelga de pliego de peticiones, en Colombia existe la huelga de no pago de obligaciones salariales, la huelga de solidaridad y la huelga política.

\section{Conclusiones}

De acuerdo con Hannah Arendt, la razonabilidad funda el reconocimiento de la existencia del otro, pero también la necesidad de ceder y comprender sus razones. Esta es la clave para la vida pública de la conciencia ${ }^{37}$ y así debería ser el actuar de nuestros operadores judiciales. Su papel de aplicadores e interpretadores de la ley debe realizarse desde la razón, porque de lo contrario estaremos sometidos al totalitarismo de los jueces. De aquí que escuchar, analizar y pensar constituyen el trípode que permite a nuestros operadores comprender este análisis y la propuesta, cuya conclusión es la siguiente:

Respecto a la problemática actual sobre los servicios públicos esenciales en Colombia y la legalidad o ilegalidad de las huelgas en dichas actividades, es claro que el CST, en su Artículo 430, no ha definido qué es un servicio público esencial y tampoco se

Oficina Internacional del Trabajo, Conferencia Internacional del Trabajo, 53.

Oficina Internacional del Trabajo, Conferencia Internacional del Trabajo, 53.

Manuel Cruz, comp. El siglo de Hannah Arendt (Barcelona: Paidós, 2007), 75. 
ha producido hasta la fecha ninguna ley que lo haga. No obstante, en la práctica, la Corte Constitucional ha indicado que el Artículo 430 debe ser leído desde los criterios constitucionales que expresaron la garantía del derecho de huelga a los trabajadores, salvo en los servicios públicos esenciales. ${ }^{38}$ En varias oportunidades, el Congreso de la República ha señalado que algunas actividades son de servicio público esencial, como el servicio de salud y los servicios públicos domiciliaros, entre otros; para ellas son aplicables los criterios del CLS y de la CEACR.

En relación con los tipos de huelga existentes en Colombia, al definir la huelga, el Artículo 429 del CST manifiesta que su ejercicio está supeditado a la presentación del pliego de peticiones, esto es, una huelga de pliego de peticiones que se efectúa por los trabajadores de un establecimiento o una empresa con fines económicos y profesionales, propuesta a un empleador y con los trámites previos indicados en las normas del CST sobre la negociación colectiva. Para que opere la huelga de la que habla el Artículo 429 debe haberse presentado un pliego de peticiones y agotado la etapa de un arreglo directo, con el fin de cumplir con los requerimientos de la norma sobre quienes deciden la huelga.

Es necesario mencionar que cuando la norma laboral habla de trabajadores, deben incluirse todos aquellos que ejercen o pueden ejercer el derecho de asociación sindical de conformidad con el Convenio 87 de la OIT y los criterios que el Comité de Libertad Sindical ha concretado, ${ }^{39}$ en interpretación del Artículo 2 del Convenio 87, que reconoce la libertad sindical sin discriminación debida a la ocupación, al sexo, a la raza, a las creencias, a la nacionalidad, a las opiniones políticas, etc., no solo a los trabajadores del sector privado de la economía, sino también a los funcionarios y a los agentes de los servicios públicos en general.

El CST solo reconoce dos tipos de huelga en Colombia: la huelga del pliego de peticiones del Artículo 429, reglamentada en este mismo estatuto y la huelga del Artículo 379 literal e), es decir, la huelga imputable al empleador por incumplimiento de las obligaciones laborales y que, por Sentencia C-201 de 2002, la Corte declara exequible, desde el entendido que, conforme a la Constitución Política, la prohibición no impide promover la huelga por solidaridad. Esta huelga no está reglamentada en el CST, por lo tanto es la organización sindical la que debe fundar los mecanismos necesarios para reglamentarla.

\footnotetext{
Colombia, Corte Constitucional, Sentencia C-450 de 4 de octubre de 1995; Colombia, Corte Constitucional, Sentencia C-085 de 1 de marzo de 1995, M. P. Jorge Arango Mejía.

39 Oficina Internacional del Trabajo, Conferencia Internacional del Trabajo, 65.
} 
Respecto a la huelga de solidaridad y la huelga política, la Corte Constitucional ha sido reiterativa sobre la importancia de los criterios de interpretación del Convenio 87 de la OIT, como parte del bloque de constitucionalidad para otorgar validez en nuestro ordenamiento interno de estas clases de huelga.

En lo atinente a las causales de la suspensión colectiva de trabajo del Artículo 450 del CST, es de gran importancia señalar que respecto de la huelga de pliego de peticiones y su posible declaratoria de ilegalidad deberá tenerse en cuenta su trámite y, en las actividades de servicio público esencial, deberán considerarse los criterios del CLS sobre esta actividad. En definitiva, respecto de la huelga por no pago de obligaciones laborales, la huelga de solidaridad y la huelga política, en caso de someterse a consideración de los operadores judiciales, se deberá actuar conforme a los criterios de los órganos de control de la OIT estudiados.

\section{Referencias}

Beaudonnet, Xavier, ed. International Labour Law and Domestic Law Subtitle: Training Manual for Judges, Lawyers and Legal Educators. Turín: OIT, 2009.

Colombia, Congreso de la República, Código Sustantivo del Trabajo. Bogotá: Legis, 2012.

Colombia, Congreso de la República. Acto legislativo 01 de 1936, "Reformatorio de la Constitución”. Bogotá: Diario Oficial No. 23.263, 22 de agosto de 1936.

Colombia, Corte Constitucional. Sentencia C-075 de 20 de febrero de 1997. M. P. Hernando Herrera Vergara.

Colombia, Corte Constitucional. Sentencia C-085 de 1 de marzo de 1995. M. P. Jorge Arango Mejía.

Colombia, Corte Constitucional. Sentencia C-1158 de 17 de noviembre de 2005. M. P. Alfredo Beltrán Sierra.

Colombia, Corte Constitucional. Sentencia C-122 de 22 de febrero de 2012. M. P. José Ignacio Pretelt.

Colombia, Corte Constitucional. Sentencia C-450 de 4 de octubre de 1995. M. P. Antonio Barrera Carbonell.

Colombia, Corte Constitucional. Sentencia C-466 de 14 de mayo de 2008. M. P. Jaime Araujo Rentería.

Colombia, Corte Constitucional. Sentencia C-473 de 27 de octubre de 1994. M. P. Alejandro Martínez Caballero.

Colombia, Corte Constitucional. Sentencia C-542 de 23 de octubre de 1997. M. P. Hernando Herrera Vergara. 
Colombia, Corte Constitucional. Sentencia C-567 de 17 de mayo de 2000. M. P. Alfredo Beltrán Sierra.

Colombia, Corte Constitucional. Sentencia C-858 de 3 de septiembre de 2008. M. P. Nilson Pinilla Pinilla.

Colombia, Corte Constitucional. Sentencia T-285 de 5 de abril de 2006. M. P. Álvaro Tafur Galvis.

Colombia, Corte Constitucional. Sentencia T-423 de 11 de septiembre de 1996. M. P. Hernando Herrera Vergara.

Colombia, Corte Constitucional. Sentencia T-568 de 10 de agosto de 1999. M. P. Carlos Gaviria Díaz.

Colombia, Corte Constitucional. Sentencia T-568 de 10 de agosto de 1999. Expediente 206.360. M. P. Carlos Gaviria Díaz.

Colombia, Corte Suprema de Justicia. "Sentencia del 12 de diciembre de 2012, referencia No. 58.697". http://webcache.googleusercontent.com/search?q=cache:apvZP NaEhV8J:190.24.134.69/sentencias/Tutelas/2013/Penal/Dr.Gustavo\%2520Enriqu e\%2520Malo\%2520Fern\%25C3\%25Alndez/Agosto/T-68350\%2801-08-13\%29. $\mathrm{doc}+\& \mathrm{~cd}=2 \& \mathrm{hl}=\mathrm{es} \& \mathrm{ct}=\mathrm{clnk} \& \mathrm{gl}=\mathrm{co}$ (acceso noviembre 20, 2013).

Cruz, Manuel, comp. El siglo de Hannah Arendt. Barcelona: Paidós, 2007.

Oficina Internacional del Trabajo. Conferencia Internacional del Trabajo. 81a reunión 1994. Informe de la Comisión de expertos en Aplicación de Convenios y Recomendaciones. Ginebra: Oficina Internacional de Trabajo, 1994.

Organización Internacional del Trabajo. Libertad sindical: recopilación de decisiones y principios del Comité de Libertad Sindical del Consejo de Administración de la OIT. 5a ed. Ginebra: Oficina Internacional del Trabajo, 2006.

Ostau de Lafont, Francisco Rafael y Leidy Ángela Niño Chavarro. "Aplicación de los Convenios de la OIT en materia de derecho de asociación sindical y negociación colectiva en las decisiones de los jueces laborales en Colombia. Prolegómenos". Derechos y Valores, núm. XIII (julio-diciembre, 2010): 162-178. 